\title{
A STUDY OF AGEING EFFECTS IN WIRE CHAMBERS
}

\author{
J. ADAM ', C. BAIRD ${ }^{2}$, D. COCKERILL ${ }^{3}$, P.K. FRANDSEN ', H.J. HILKE ', H. HOFMANN ', \\ T. LUDLAM ${ }^{4}$, E. ROSSO ${ }^{1}$, D. SORIA ${ }^{1}$ and D. VAUGHAN ${ }^{\prime}$ \\ 'CERN, Geneva, Switzerland \\ 'Queen Mary College, London University, England \\ Rutherford Appleton Laboratory, Oxon., England \\ 'Brookhaten National Laboratory, USA
}

\begin{abstract}
Following the observation of deposits on an anode wire from the AFS central detector at the ISR some two years ago, systematic tests were carried out to establish the origin of the silicon, which was detected as a major component, and to possibly find techniques which could reduce this deposition process. In irradiated test chambers, filled with $\mathrm{Ar} / \mathrm{C}_{2} \mathrm{H}_{6}$, with and without methylal, and $\mathrm{Ar} / \mathrm{CO}_{2}$, gain reductions were observed, initially at $-4 \% / 10^{16} \mathrm{e} / \mathrm{mm}$ but increasing finally to $\sim 20 \% / 10^{16} \mathrm{e} / \mathrm{mm}$. High voltage instabilities occurred after about $2.3 \times 10^{16} \mathrm{e} / \mathrm{mm}$. The introduction of a cold trap, which should absorb heavier silanes, did not halt the ageing process, nor did prechambers with HV. Tests with a perspex chamber also showed ageing, but without silicon as a major component. Flat cathode chambers did not appear to age. at least to $\sim 15-20 \times 10^{16} \mathrm{e} / \mathrm{mm}$.
\end{abstract}

\section{Introduction}

Ageing tests were carried out to establish a lifetime for the AFS central detector at the ISR [1]. The chamber operates with $50 / 50 \mathrm{Ar} / \mathrm{C}_{2} \mathrm{H}_{6}$ at a gain of $(3-4) \times$ $10^{4}$. The gas is mixed from separate banks of argon and ethane cylinders and partially (50\%) recirculated [2]. At typical ISR luminosities of $1.4 \times 10^{31} \mathrm{~cm}^{-2} \mathrm{~s}^{-1}$ the inner crown of the detector collects $\sim 6 \times 10^{8}$ electrons per $\mathrm{mm}$ of wire/s, averaged over a wire length of $1.4 \mathrm{~m}$. Over the past three years of operation the inner crown has accumulated $\sim 0.7 \times 10^{16} \mathrm{e} / \mathrm{mm}$ wire.

After one year a broken 30 micron nichrome anode wire was removed from the chamber. It was examined with an electron microscope and found to be covered with a smooth layer of silicon, with sulphur on the first few atomic layers. Also present were blobs of similar composition, 10-50 microns thick, every $0.3 \mathrm{~mm}$ along the wire. No further wires have broken on the AFS and no problems found whith HV stability, efficiency or pulse height, though we may be insensitive to small drops in gain.

Other experiments have found problems due to silicon deposition, including NA1l at CERN [3]. This type of ageing is probably different from that of carbon deposition on anodes, where no silicon is seen [4,5]. In addition there are reports on the polymerisation properties of ethane [6], lifetime studies for chambers at Isabelle [7] and the use of methylal in flat cathode and wire cathode chambers [8] and ageing effects in various gases [9].

\section{Test chambers}

The tests were carried out by irradiating small drift chambers having roughly the same geometry and construction as part of the central detector. A typical "G10" chamber is shown in fig. 1. It was constructed with side walls and end plates of $5 \mathrm{~mm}$ thick G10* and cover plates of aluminium. Gas seals between the covers and chamber were made with $\mathrm{O}$ rings **. Araldited to each side wall was a $3 \mathrm{~cm}$ diameter quartz window, to view the chamber internally, and to each end plate a 6 $\mathrm{mm}$ diameter $\mathrm{Cu}$ pipe for gas.

The cathode and potential wires, $24.5 \mathrm{~cm}$ long, were made from 100 micron $\mathrm{CuBe}$ and usually held at $-3.9 /-1.9 \mathrm{kV}$ respectively. The 8 anode wires (at ground, $8 \mathrm{~mm}$ apart, with the potential wires between them) were made from 30 micron nichrome wire ${ }^{\dagger}$, composition $75 \% \mathrm{Ni}, 25 \% \mathrm{Cr}, 5 \% \mathrm{Al}, \mathrm{Si}+$ others. The wires were held in place using crimped feedthroughs located in the endplates. With $50 / 50 \mathrm{Ar} / \mathrm{C}_{2} \mathrm{H}_{6}$ the gas gain was $-3 \times 10^{4}$.

Set into the top cover plate were two collimators to define the control and test positions. They were each approximately $2 \mathrm{~mm}$ wide $\times 3 \mathrm{~mm}$ long $\times 5 \mathrm{~mm}$ deep with the long side parallel to the wires. The collimators were placed $12 \mathrm{~cm}$ apart along the wire direction, $6.5 \mathrm{~cm}$

\footnotetext{
* From Stesalite.

** Nitrile, synthetic, $2 \mathrm{~mm}$ diameter.

† Stableohm 800 from California Fine Wire Company.
} 


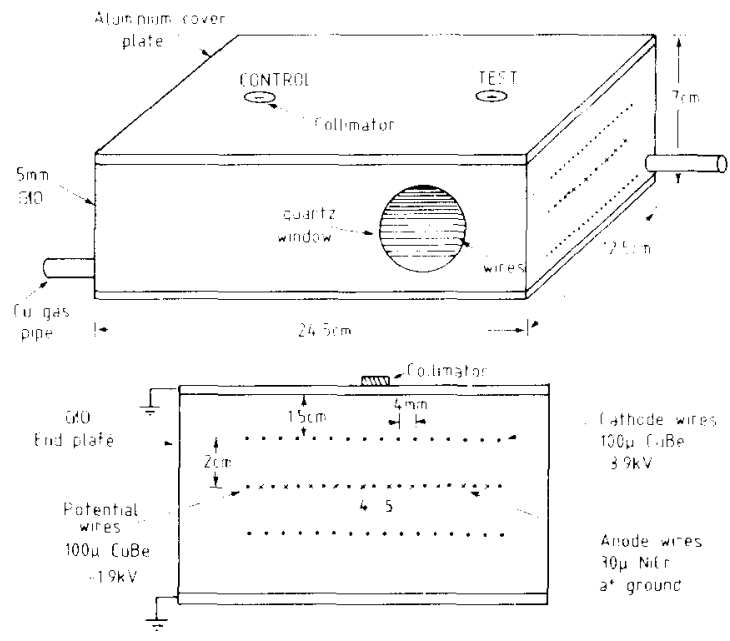

Fig. 1. G10 test chamber.

from the end plates, directly over anode wires 4 and 5 . Since these wires received most of the irradiation they were the ones monitored during the tests. By monitoring both wires any anomalies on a single wire could be detected.

The spread of radiation along anode wires 4 and 5 was found by turning the test position collimator through $90^{\circ}$ and measuring the currents drawn on adjacent anode wires. The distribution is shown in fig. 2 and has a fwhm of $-20 \mathrm{~mm}$. This value was used to calculate the total charge collected per $\mathrm{mm}$ wire during the tests.

To be free from materials containing silicon, a "perspex" chamber was constructed, using the same wire geometry as above. It had perspex end plates kept apart with four aluminium rods. Aluminised mylar was wrapped around the chamber and held in place at the end plates with double sided scotch tape. Collimators, similar to those for the Glo chamber, were positioned in a plate which rested on top of the chamber.

Finally. to observe ageing using flat cathodes, two chambers were made with square cross-section aluminium bars $1 \mathrm{~cm} \times 1 \mathrm{~cm} \times 25 \mathrm{~cm}$ long with a single 30 micron nichrome wire down the centre. Gas was supplied through $2 \mathrm{~mm}$ diameter $(\mathrm{u}$ pipe araldited to the aluminium. The collimators were positioned so that about $10 \mathrm{~mm}$ of wire was irradiated. The chambers were operated with $+1.8 \mathrm{kV}$ on the anode giving a gain $-3 \times 10^{4}$ in $50 / 50 \mathrm{Ar} / \mathrm{C}_{2} \mathrm{H}_{6}$.

\section{Test procedure}

The tests were carried out on two gas lines with a similar layout (fig. 3). Line 1 consisted of $\mathrm{Cu}$ pipe, cleaned with alcohol, and a silicon oil bubbler. In initial tests, and for those with methylal, a filter of KVD granules (nitrium aluminium silicate) was placed before the flow meter. It was removed but did not appear to affect the ageing. Line 2 was made to be as clean and free from silicon compounds as possible. It consisted of inox pipe (heated to $150^{\circ} \mathrm{C}$ for $24 \mathrm{~h}$ then ultrasonically cleaned in freon) and a distilled water bubbler. Only the perspex chamber was tested in this line.

Gas for both lines was supplied from premix $50 / 50$ $\mathrm{Ar} / \mathrm{C}_{2} \mathrm{H}_{6}$ from Carbagas (purity $46 / 35$ ) with $<5 \mathrm{ppm}$ for $\mathrm{H}_{2} \mathrm{O}$ and $\mathrm{O}_{2}$. The $-50 / 50 \mathrm{Ar} / \mathrm{CO}_{2}$ test was setup using separate cylinders at a remote rack. This was connected to the flow meter on line 1 with $-10 \mathrm{~m}$ of plastic (Rilsan) pipe. The two methylal tests, atso on line $\mathrm{I}$. were set up by passing $\sim 50 \%$ of the premix $\mathrm{Ar} / \mathrm{C}_{2} \mathrm{H}_{6}$ through liquid methylal at $0^{\circ} \mathrm{C}$, giving a mixture of $\sim 60 / 35 / 5 \mathrm{Ar} / \mathrm{C}_{2} \mathrm{H}_{6} /$ methylal.

At the start of very test, and at roughly $24 \mathrm{~h}$ intervals thereafter, the pulse height spectra on anodes 4 and 5

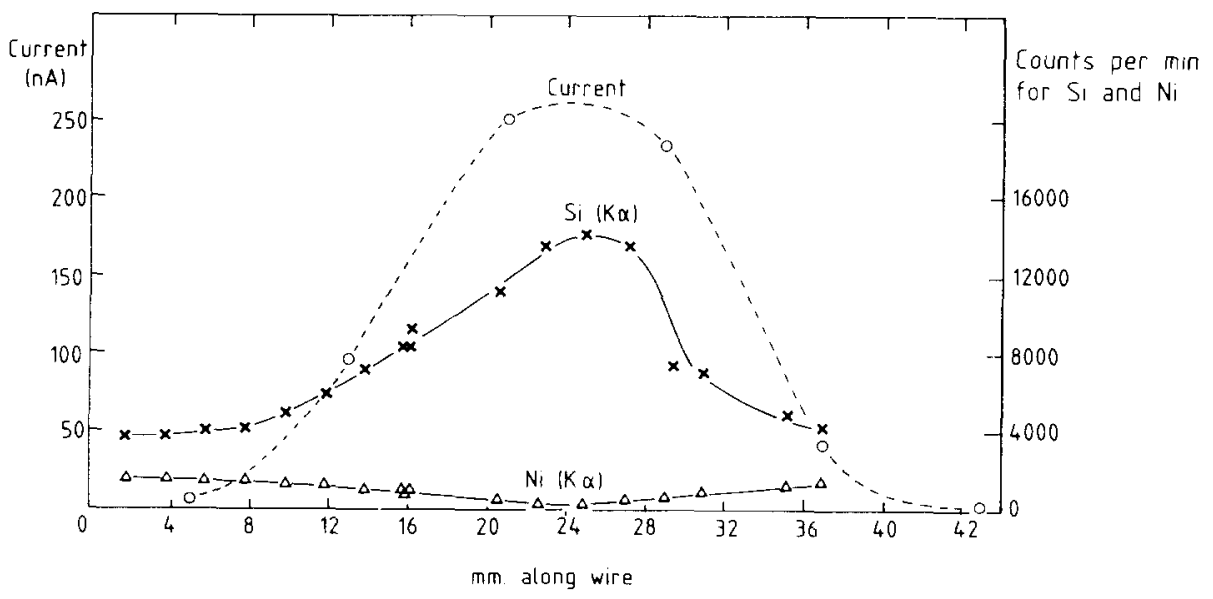

Fig. 2. Current measurements for the distribution of radiation and count rates for Si and Ni along an anode wire. 


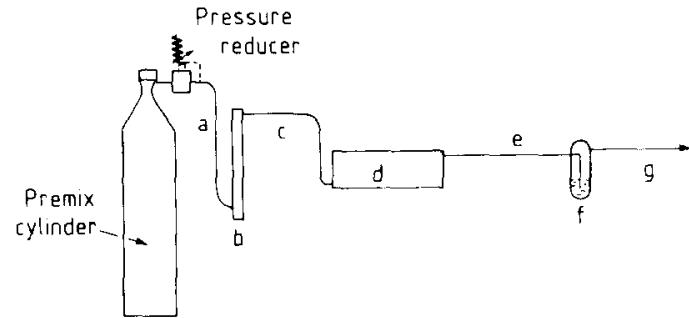

GAS LINE

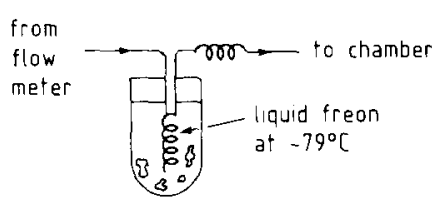

COLD TRAP

Fig. 3. Gas Lines and cold trap.

\begin{tabular}{lll}
\hline & Line $\mathrm{l}$ & Line 2 \\
\hline a, c, e. & $2 \mathrm{~m}, 6 \mathrm{~mm}$ diameter Cu pipe & $50 \mathrm{~cm}, 6 \mathrm{~mm}$ diameter inox \\
b. & Flow meter & Flow meter \\
d. & Test chamber & Perspex chamber \\
f. & Silicon oil bubbler, DC704 & Distilled water bubbler \\
g. & $10 \mathrm{~m}$ plastic pipe & $5 \mathrm{~m}$ plastic pipe. \\
\hline
\end{tabular}

were recorded, at both the control and test positions, using a $1 \mathrm{mCi}{ }^{55} \mathrm{Fe}$ source. A $100 \mathrm{mCi}{ }^{55} \mathrm{Fe}$ source was then left at the test position and the currents (typically $\sim 100 \mathrm{nA}$ ) from anodes 4 and 5 recorded. Temperature, pressure and humidity were recorded continuously. The change in gain at the test position was found by comparing the ${ }^{55} \mathrm{Fe}$ pulse height at the test position to that at the control position for the same anode wire. This method removed problems arising from peak position movement due to changes in pressure, temperature and the gas mix itself.

The spectra were measured using the same amplifier chain. This consisted of a preamplifier, $300 \mathrm{~ns}$ integrating amplifier and pulse height analyser. A calibration pulse, corresponding to a specific charge on the wire, was fed to the preamplifier to monitor electronic gain and resolution.

Some tests were carried out at higher gas gain. In such cases the HV was lowered, before taking the pulse height spectra, to avoid saturation effects. Each test took 1-3 weeks, stopping either due to high currents and trippping or if the spectra were clearly degraded.

\section{Results}

\section{1. "G10" chambers, 50/50 $\mathrm{Ar} / \mathrm{C}_{2} \mathrm{H}_{6}$, line I}

In all cases (6 tests) there was a reduction in pulse height at the test position. The ${ }^{55} \mathrm{Fe}$ peak became de-
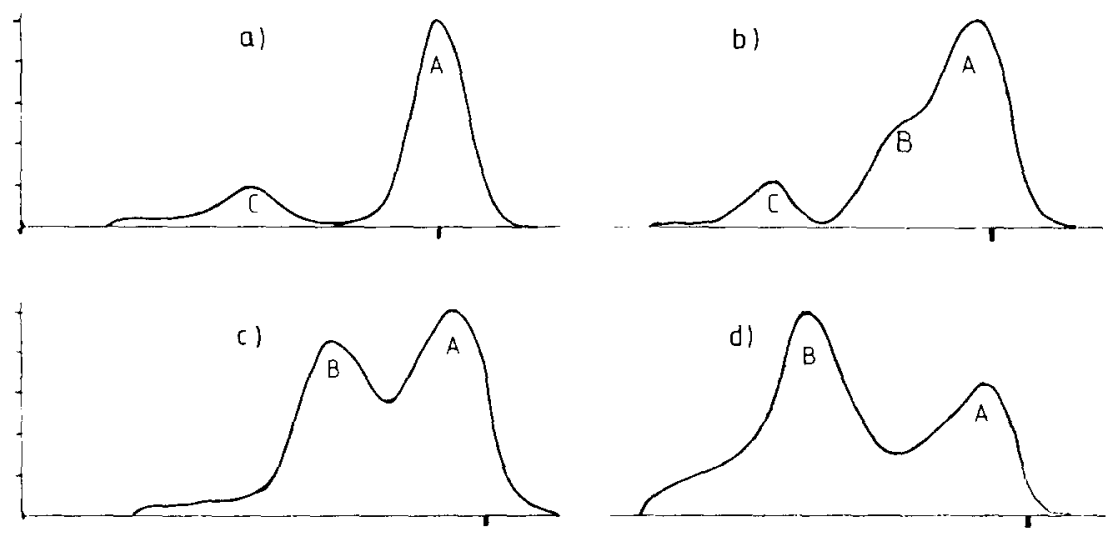

Fig. 4. Successive ${ }^{55} \mathrm{Fe}$ distributions during a test: $\mathrm{A}$, main peak; B, second peak; $\mathrm{C}$ escape peak. 
graded, as shown by successive distributions in figs. 4 (a-d). Initially the main peak $A$ dropped at $\sim 4 \% / 10^{16}$ $\mathrm{c} / \mathrm{mm}$ until the appearance of a second peak $B$ at $-(1-2) \times 10^{1 \mathrm{~h}} \mathrm{e} / \mathrm{mm}$. This second peak dropped at $-20 \% / 10^{1 \mathrm{~h}} \mathrm{e} / \mathrm{mm}$ with the number of counts under the peak gradually increasing at the expense of the upper peak A. Eventually A also dropped at $\sim 20 \% / 10^{1 \%}$ $\mathrm{e} / \mathrm{mm}$. The decrease in the current drawn from the anodes reflected this general drop in gain. The control resolutions were normally well behaved throughout and generally within $(17 \pm 1) \%$. Movements in the control peak position corresponded to observed changes in temperature and pressure.

On early tests the end plates were covered with silicolloid to stop HT discharges between anode and potential wires. This was not used in later tests though no noticeable change was seen in the ageing. Replacing cathode wires after a test did not improve the spectra in contrast to replacing the anode wires which restored chamber performance. Some chambers were left for a period of time without HV (2 days to 3-4 months) and in most cases an improvement $(-10-30 \%)$ in the pulse height spectra was seen. However this quickly returned to previous levels with the reintroduction of the 100 mCj source. Placing a flat cathode chamber (see above) with $\mathrm{HV}$ before a G10 chamber did not stop ageing.

High currents and HV instability occurred in 2 tests at $-(1-2) \times 10^{16} \mathrm{e} / \mathrm{mm}$ at normal gain $\left(3 \times 10^{4}\right)$ and at $-(2-3) \times 10^{16}$ in 2 tests at higher $\left(-6 \times 10^{4}\right)$ gain. The high currents often persisted if the $100 \mathrm{mCi}$ source was removed but ceased if the HV was turned off and on without any source present. However even the 1 mo $i$ source was then capable of triggering the high surrents.

A cold trap of liquid freon at $-79^{\circ} \mathrm{C}$ (see fig. 3) was placed hefore a $G 10$ chamber in an attempt to remove heavy silanes and silicon oils. Ageing still occurred. though peaks $A$ and $B$ fell at $\sim 7 \% 10^{\mathrm{ith}} \mathrm{emm}$ and the chamber was stable to $-10 \times 10^{16} \mathrm{c} / \mathrm{mm}$.

Tests with $\mathrm{Ar} / \mathrm{C}_{2} \mathrm{H}_{0}$ methylal also showed ageing. with double peaks appearing at $-0.5 \times 10^{\mathrm{k}} \mathrm{c}^{\circ} \mathrm{mm}$. The single $\mathrm{Ar} / \mathrm{CO}_{2}$ test showed ageing with the chamber unstable at $-1.5 \times 10^{16} \mathrm{e} / \mathrm{mm}$. This test was done with a modified Glo chamber which was placed inside an aluminium container with collimators of only $1 \mathrm{~mm}$ diameter.

\section{2. "Perspex" chamber, $50 / 50 \mathrm{Ar} / \mathrm{C}_{2} \mathrm{H} / \mathrm{l}$. Ine'?}

Two tests were carried out, one to $2 \times 10^{1 / 1} \mathrm{e} / \mathrm{mm}$ the other to $8 \times 10^{16} \mathrm{e} / \mathrm{mm}$. In both the double peak behaviour occurred with a loss in gain similar to that for the $G 10$ tests. In the test to $8 \times 10^{16} \mathrm{e} / \mathrm{mm}$ the chamber was unstable from $\sim 2 \times 10^{16} \mathrm{e} / \mathrm{mm}$ and eventually took high currents.

\subsection{Flat cathode chambers, $50 / 50,4 r / 6, H_{0}$. line'}

The two chambers (A and B) were connected in series with chamber $B$ on the downstream bubbler side. The chambers were irradiated simultaneously with two $100 \mathrm{mCi}{ }^{45} \mathrm{Fe}$ sources. Two tests were carricd out. Chamber $A$ showed little drop in pulse height $(<3 \%)$ in

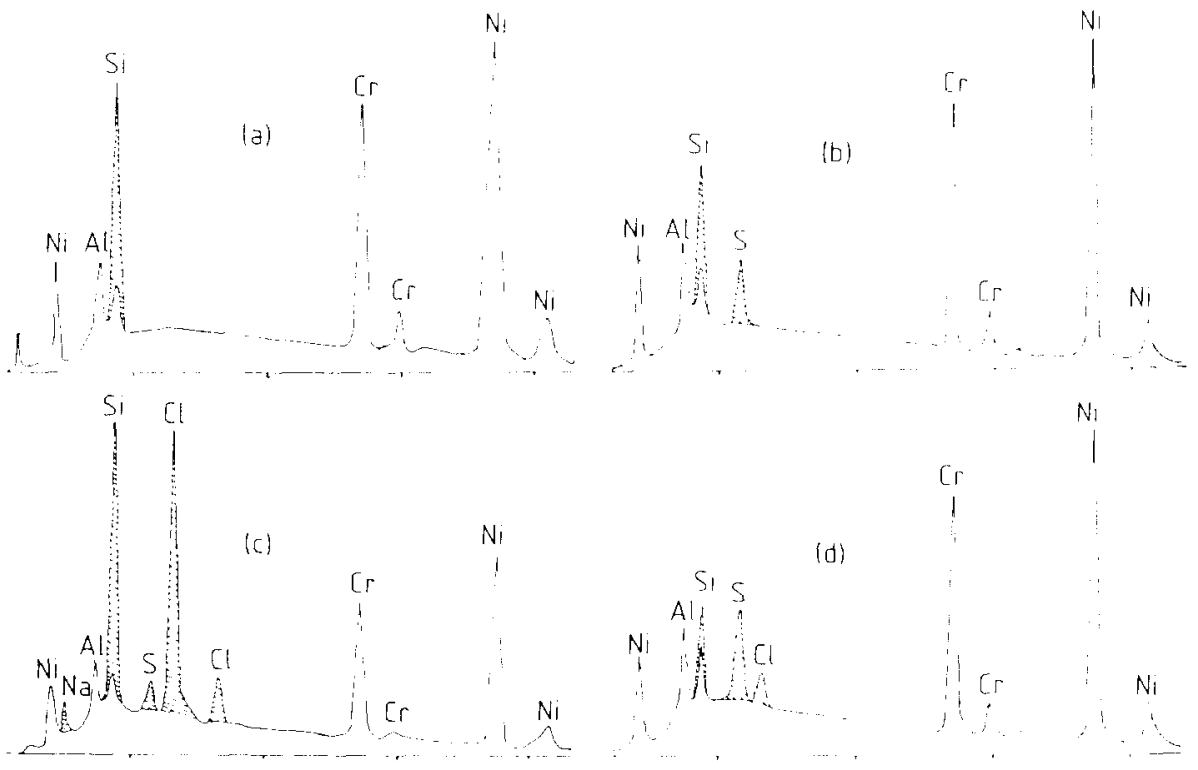

Fig. 5. Energy dispersive analyses: (a-c) for $G 10$ chamber anode wires. (a) $\mathrm{Ar} / \mathrm{C}_{2} \mathrm{H}_{6}:(\mathrm{h})+\mathrm{cold}$ trap: (c) Ar/(C) $:$ (d) for the perspex chamber anode wire 
either test, to $22 \times 10^{16} \mathrm{e} / \mathrm{mm}$ and $15 \times 10^{16} \mathrm{e} / \mathrm{mm}$. Chamber $\mathrm{B}$ showed a deterioration in resolution in the test to $15 \times 10^{16} \mathrm{e} / \mathrm{mm}$. This changed from $15 \%$ to $20 \%$ at $2 \times 10^{16} \mathrm{e} / \mathrm{mm}$ but then remained constant. No drop in the peak position was seen. In the test to $22 \times 10^{16}$ chamber $B$ had intermittent problems though by the end of the test the peak showed little if any drop and had a resolution of $15 \%$.
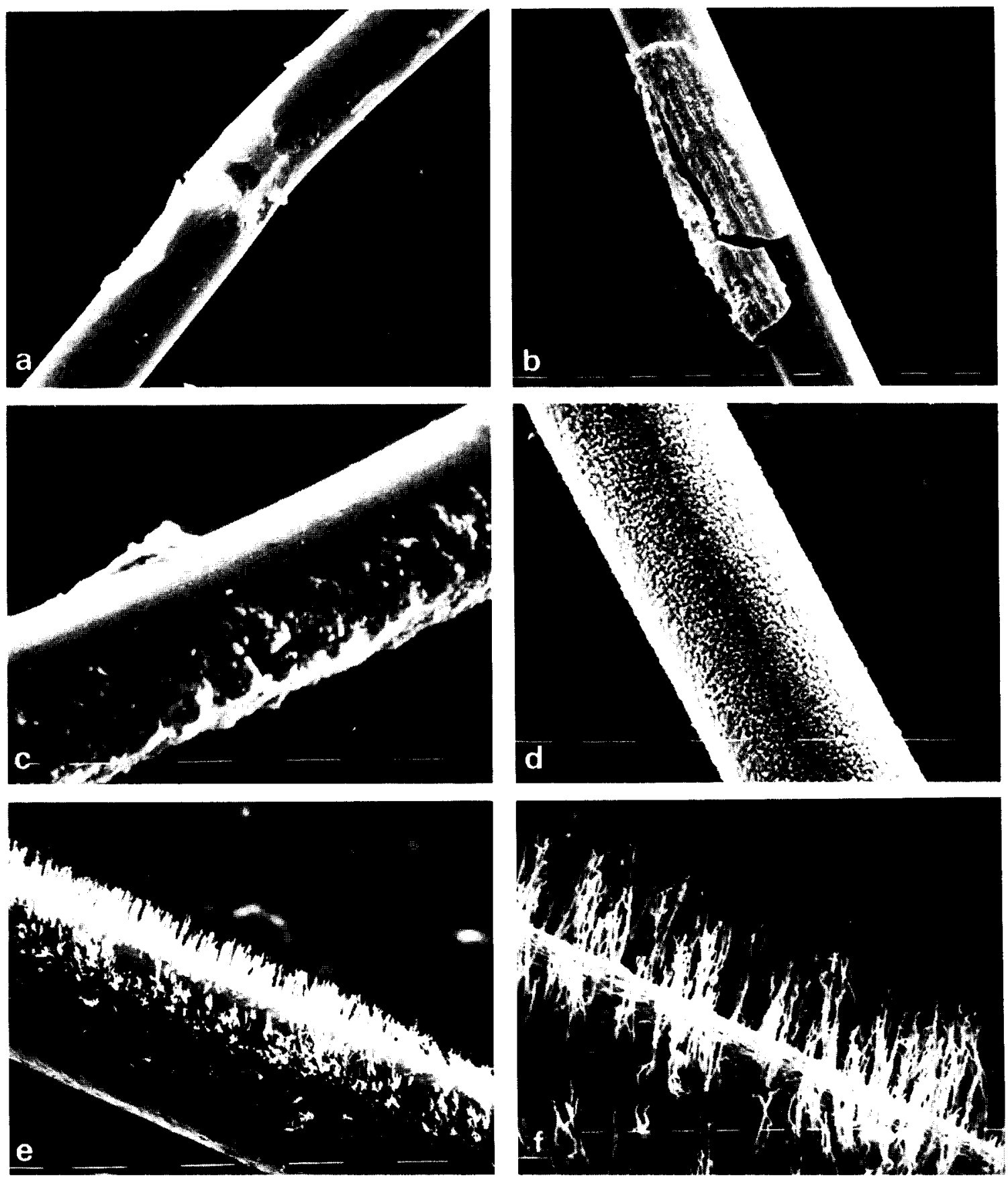

Fig. 6. Deposits on anode wires. (a-c) from the GlO chambers: (a) $\mathrm{Ar} / \mathrm{C}_{2} \mathrm{H}_{6}$; (b) + methylal: (c) $\mathrm{Ar} / \mathrm{CO}_{2}:$ (d) from the perspex chamber: (e.f) from the G10 chamber and cold trap. 


\section{Wire analysis}

Most wire analysis was done on the electron microscope at CERN. This uses an energy dispersive technique which can detect the presence of elements as low as sodium. A few wires were analysed at Oxford where the microscope uses a wavelength dispersive technique which is sensitive down to boron and can thus detect carbon and oxygen.

\subsection{The "GIO" chambers}

All the anode wires taken from Gl0 chambers had a deposit containing silicon at the test position. Cathode wires analysed at the test position appeared to be clean. A photograph of one of the anode wires, from a test with $\mathrm{Ar} / \mathrm{C}_{2} \mathrm{H}_{6}$ after $1.1 \times 10^{16} \mathrm{e} / \mathrm{mm}$. is shown in fig. 6a where the wire has been purposely bent to crack and illustrate the surface. The energy dispersive analysis for this wire is shown in fig. $5 \mathrm{a}$. The silicon signal is shown shaded above the distribution expected for a normal nichrome wire, which contains $\sim 1 \%$ silicon. The layers tended to be smooth, hard, 1-2 microns thick, and from the image on the monitor screen. bad conductors. Analysis at Oxford showed the composition of such layers to be $\mathrm{SiO}_{2}$ with no $(<0.5 \%)$ carbon.

Fig. 2 shows the count rate for silicon and nickel at 2 $\mathrm{mm}$ intervals along an anode wire. at the test position. The count rate for silicon increases as the layer gets thicker while the nickel count rate from the wire drops. The count rates are shown juxtaposed with the measurements for the radiation distribution along a wire.

A wire from one of the $\mathrm{Ar} / \mathrm{C}_{2} \mathrm{H}_{6} /$ methylal tests, after $-3 \times 10^{16} \mathrm{e} / \mathrm{mm}$, is shown in fig. $6 \mathrm{~b}$. Most of the silicon layer has broken away, probably when the wire was drawn out from the chamber. The analysis for the layer was similar to that shown in fig. 5 a.

The $\mathrm{Ar} / \mathrm{CO}_{2}$ wire analysis is shown in fig. $5 \mathrm{c}$ and one of the wires shown in fig. $6 \mathrm{c}$. In addition to silicon there was a high chlorine signal together with some sodium and sulphur. These additional elements may have come from the container for the modified G10 chamber, the cables that were also inside, or the plastic pipe and remote rack assembly.

A wire from the "G10" chamber test with the cold trap is shown in figs. 6 e,f. The surface is covered with fine filaments, under 0.1 microns thick, probably of silicon. An analysis of the general wire surface (fig. 5b) showed that sulphur was also present. Due to wire handing we cannot be sure if the filaments surrounded the whole wire or if indeed they have grown in a favoured direction.

\subsection{The perspex chamber}

The wires from the perspex chamber tests showed little, if any, silicon present on the surface layer. A wire after $8 \times 10^{16} \mathrm{e} / \mathrm{mm}$ is shown in fig. $6 \mathrm{~d}$. The surface was soft and easy to remove. The analysis is shown in fig. $5 \mathrm{~d}$. where sulphur and chlorine are the main components. The silicon peak is slightly above that for aluminium whereas for clean wire it is normally just below. This is probably due to surface effects though even if silicon is present it is much less than that seen for the analyses in figs. $5(\mathrm{a}-\mathrm{c})$, for up to eight times more irradiation. Wires analysed at Oxford, after $2 \times$ $10^{16} \mathrm{e} / \mathrm{mm}$, showed chlorine, sulphur and oxygen to be present but no silicon.

\section{Conclusions}

All tests with the G10 chambers showed anode contamination with silicon present as a major component. This is in contrast to the tests with the perspex chamber and water bubbler, where contamination was mainly due to chlorine and sulphur (probably from the plasticisers used to make the perspex or from the scotch tape), and to the flat cathode tests where no ageing was seen.

The perspex tests might rule out the gas itself and the pressure reducer as being responsible for the silicon ageing. However the water bubbler may act as an inhibitor. Water vapour is added at $-50 \mathrm{ppm}$ to gas for the wire chambers on an experiment at CERN, where it is claimed to extend their lifetime [10]. Whether this is against silicon or carbon ageing is not known.

This leaves the G10 chamber, the copper piping and DC704 silicon oil bubbler as possible contaminants. The G10 is made from fibreglass bonded with epoxy. It is manufactured with a layer of siliconised paper on its surface. The $O$ rings in that chamber were greased with Dow Corning High Vacuum grease (suitable for pressures down to $10^{-6}$ Torr) for early tests. These were wiped and cleaned to remove as much grease as possible, though unfortunately not with $\mathrm{KOH}$ to dissolve the grease. Used and unused $O$ rings were examined under an electron microscope and, apart from the silicon filler in the bulk material, showed a high silicon level on the surface.

The flat cathode tests showed practically no ageing despite using the same gas line as the G10 chamber tests. However, we are unsure about the importance of cathode geometry in the ageing process and so we cannot say whether the copper piping and silicon oil bubbler are ruled out as contaminants.

Clearly further tests are required to pin point the source of silicon. We hope to do tests with the $O$ rings and G10 plates placed upstream in the gas line to see if the flat cathode chambers then show silicon ageing. We have inserted flat cathodes in one of the G10 chambers and we will repeat the $G 10$ tests using a water hubbler. 


\subsection{The deposition process}

Since we have not identified the source of the ageing we cannot be sure about the deposition process. However there are a number of papers concerning the formation of thin silicon films produced by electron bombardment $[11-14]$ and sources of contamination in high vacuum plants [15,16] which may have a particular relevance to the effects we have observed.

Thin films of silica were produced by leaving a bowl of DC704 in an evaculated chamber and bombarding an anode plate with electrons from a cathode gun at a current density of $\sim 0.4 \mathrm{~mA} / \mathrm{cm}^{2}$ and an accelerating voltage of $50-300 \mathrm{~V}$. The oil molecules temporarily adsorbed onto the surface of the anode were found to polymerise by cross linking to adjacent molecules under the action of the electron bombardment. The slowly growing deposit then continued to be degraded, releasing hydrogen and carbon, leaving an almost pure layer of silica with a resitivity of $-10^{14} \Omega \mathrm{cm}$.

The above could explain the double peak structure seen in the tests. The area of the wire subjected to most of the irrradiation develops a layer which becomes thicker and a better insulator. This gives rise to the second peak. Outside this region the layer forms more slowly, accounting for the main peak behaviour. However the current density of electrons onto the anode wires in our tests is only $-5 \mu \mathrm{A} / \mathrm{cm}^{2}$ and is not continuous, coming from ${ }^{55} \mathrm{Fe}$ photons converting in the gas. This would be offset if a contaminant with a higher vapour pressure than DC704 were present. DC704 has a vapour pressure of $\sim 10^{-8}$ Torr at room temperature whereas the silicon grease is recommended for vacuum down to $10^{-6}$ Torr.
The report by Holland [11] also refers to properties of hydrocarbon polymer films which can be electrically conducting or insulating according to the carbon to hydrogen ratio and the degree of cross linking. This could be of interest for cases concerning carbon deposition on anodes.

We would like to thank M. Albrow, C. Fabjan, A. Minten and $W$. Willis for their support during this project, and J.C. Berset and A. Rudge for their assistance with the electronics.

\section{References}

[1] D. Cockerill et al., Nucl. Instr. and Meth. 176 (1980), 159.

[2] P.K. Frandsen, CERN / EF 82-13.

[3] M. Turala et al., Nucl. Instr. and Meth. 205 (1983), 141.

[4] A.J.F. den Boggende et al., J. Sci. Instr. 2 (1969), 701.

[5] A. Smith et al., Nucl. Instr. and Meth. 192 (1982) 475

[6] D. Friedrich et al., CERN EP 77-10.

[7] H. Okuno et al., BNL 25887.

[8] G. Charpak et al., Nucl. Instr. and Meth. 99 (1972) 279

[9] A.R. Farugi et al., Proc. 4th Taniguchi Symp. on Biophysics (1978) p. 367; IEEE Trans. Nucl. Sci. 27 (1980) 644.

[10] F. Schneider, private communication.

[11] L. Holland. Thin Film Microelectronics (Chapman and Hall Ltd, 1965) p. 157.

[12] L. Holland et al., Vacuum, 14 (1964) 325.

[13] T.P. Woodman, Brit. J. Appl. Phys. 16 (1965) 359.

[14] R. Christy, J. Appl. Phys. 31 (1960) 1680.

[15] L. Holland et al., Rev. Sci. Instr. 34 (1963) 377

[16] G. Love et al.. Scanning 4 (1981) 32. 